доров, Москва, 2007. - 616 с.

Шипулина, Л. А. Формирование профессионализма будущих экономистов средст- вами новых информационных технологий. Дис...канд. пед. наук, Ставрополь, 2004.

УДК 316.28

Грин Надежда Васильевна,

к.филол.н., дочент, доиент кафедры «Иностранные языки», ФГБОУ ВО «Ангарский государственный технический университет», e-mail: greennadezhda@gmail.com

ТЕХНИЧЕСКИЙ ТЕКСТ КАК ЕДИНИЦА КОММУНИКАЦИИ

Green N.V.

\title{
TECHNICAL TEXT AS A UNIT OF COMMUNICATION
}

Аннотация. В статье рассматривается метафора как коммуникативное явление, реализуюшееся в иелом тексте. Как единица коммуникации технический текст имеет свою спеичифику, определяемую, прежде всего особенностями функционирования сообщений.

Ключевые слова: метафора, технический текст, коммуникативное явление, языковые средства.

Abstract. The article considers metaphor as a communicative phenomenon realized in the whole text. As a unit of communication, a technical text has its own specifics, determined primarily by the peculiarities of the functioning of message.

Keywords: metaphor, technical text, communicative phenomenon, language means.

Основным показателем осуществления речевой деятельности является создание или понимание текста. К сожалению, в лингвистике пока нет ещё однозначного определения этой единицы. Однако можно назвать ряд признаков, которые позволяют охарактеризовать её достаточно полно. С этой точки зрения можно назвать следующие признаки.

Прежде всего, текст - это коммуникативная единица. Как таковую её характеризует наличие коммуникативного задания (сверхзадачи, если речь идёт об опосредованном воздействии на адресата, как например, в случае художественного произведения). Другими словами, являясь результатом целенаправленной деятельности, текст всегда отражает определенную прагматическую установку его создателя.

Как единице тексту свойственна целостность, смысловая законченность с точки зрения его автора по отношению к имевшемуся у него коммуникативному намерению. Этот признак текста проявляется в структурно-смысловой организации произведения. Наконец, третья характеристика текста - это его социальная обусловленность / детерминированность.

Текст является центральным звеном любого цикла занятий на любом этапе обучения. Учебные тексты, независимо от того, составлены они авторами учебников, адаптированы или заимствованы из оригинальных источников без какой-нибудь обработки, должны сохранять все релевантные черты.

Другими словами, на любой ступеньке обучения, текст должен быть аналогом реального конкретного типа/жанра текста. Содержание и языковое оформление текста часто оказываются подчиненными языковому материалу: он составляется/адаптируется автором так, чтобы ознакомить учащихся с новыми языковыми единицами (показать их значение, сочетаемость и так далее).

Многочисленные исследования метафоры свидетельствуют о том, что в настоящее время в развитии теории метафоры начинает превалировать коммуникативнотекстовый подход, для которого метафора это, прежде всего, коммуникативное явление, реализующееся в целом тексте $[1,5,9]$. Коммуникативно-текстовый подход трактует метафору гораздо шире понятия «proper metaphor». По Э. МакКормаку, она представляет собой «глобальную метафору, которой подчинен весь текст, который сам по 
себе и может быть этой метафорой» [8].

При таком подходе к метафоре коммуникативно-прагматическая трактовка текста представляется нам особенно важной.

В свете последних исследований языка и речевой деятельности согласимся с мнением В.В. Колесова о том, что передача информации (знания в понимании В.В. Колесова) это есть трансляция знания, накопленного человечеством и передаваемая «учителем». Коммуникация составляет один из уровней процесса общения, в который включены процесс передачи знаний (трансляция) и появление нового знания (трансмутация) [4]. Таким образом, на современном этапе развития коммуникативной лингвистики стоит говорить не о коммуникации, а о межкультурной коммуникации, то есть общении, поскольку данное понятие более полно и глубоко отражает сущность языка и речевой деятельности.

С этой точки зрения, определим текст как систему накопленного знания, структурно организованную посредством языковых знаков, используемых участниками общения с целью получения нового знания (познания).

В данной статье метафора рассматривается в научно-популярном техническом тексте. Как единица коммуникации технический текст имеет свою специфику, определяемую, прежде всего особенностями функционирования сообщений. Одной из таких особенностей является его адресность. Известное выражение Ю.Н. Караулова, что за каждым текстом стоит языковая личность, имеет методологическое значение применительно и к научно-популярным техническим текстам, поскольку автор выступает как создатель популярного метатехнического текстового пространства.

Участниками опосредованного текстом коммуникативного акта являются субъект речи и адресат речи. Субъект речи в научно-популярных технических текстах ориентируется на определенного получателя, учитывая его социальные и ментальные модели, его практические интересы. В научно-популярных технических текстах все усилия субъекта речи направлены на то, чтобы показать адресату речи, что предлагаемый ему научно-технический материал по своей сложности доступен его пониманию, что его интеллектуальный уровень достаточен для общения.

В научно-популярных технических текстах для раскрытия содержания неизвестных или малопонятных явлений и процессов автор пользуется различными языковыми средствами, приемами и способами.

Одним из таких средств является метафора, которая проявляет и в научнопопулярных технических текстах свои характерные признаки: образность, антропоцентризм, ориентации. на адресата (получателя). Адресат, воспринимая метафору, которую создает автор, включается в процесс познания смысла. Его концептуальная система начинает настраиваться на процесс смыслопорождения.

Таким образом, метафора, это с одной стороны, устойчивый компонент концептуальной системы автора, a, с другой, это креативная деятельность концептуальной системы получателя. Креативная сила метафоры способна совмещать несовместимое, ассоциативно-образное, выявляя новые свойства в познаваемой действительности и создавая новые смысловые пласты в вербализуемых при ее посредстве понятиях.

Однако метафора используется не только тогда, когда нет других средств для адекватного выражения некоторого нового содержания, но и тогда, когда ее образность, выразительность и экономность помогают более четко и ясно понять замысел автора. Метафоричность текста создает условия для появления смысла в коммуникации. Освоение смыслового и содержательного богатства метафорического технического текста возможно в результате сложного и многогранного процесса понимания.

Процесс понимания текста заключается в его способности превращаться в знания. По словам Г.И. Богина, такое превращение имеет форму образования понятий. Понимание текста, по его мнению, это не результат знания и познания, а условие возникновения знаний [2]. Специфика научнопопулярных технических текстов обусловлена сложностью предмета, поэтому вся организация текста направлена на преодоление информационного барьера, возникающего в результате разного уровня знаний коммуникантов. Осуществляется целая система действий, составляющих понятие «популяризации» научной и технической информации. Основная задача популяризации состоит в том, чтобы адаптировать знания 
автора к знаниям адресата, это происходит благодаря средствам метафоризации.

В научно-популярном тексте метафора позволяет предельно экономно и в то же время с исчерпывающей точностью раскрыть сущность явления, вычленить его из ряда смежных явлений, включить в определенную парадигму. Эти внутренне присущие свойства метафоры позволяют считать ее весьма эффективным приемом и наиболее динамичным элементом системы информирования, реализуемой в научнотехническом тексте.

Стремительное развитие науки и техники, открытия и изобретения сложнейших аппаратов и механизмов требовали их популяризации не только в научной сфере. С развитием науки и техники развивается и стиль изложения, требуются новые языковые средства выражения. Доступность сложных описаний, их наглядность предъявляют к языку особые требования. Язык технических текстов должен сочетать в себе элементы, как научного повествования, так и характерные черты других стилей языка. Язык как постоянный процесс переструктурирования семантического поля обеспечивает нас метафорами необходимыми для освоения потока новой информации и в какой-то степени выполняет функцию средства, обеспечивающего адаптацию человека к изменяющимся условиям. Метафора по отношению к языку является его динамическим принципом. Каждое новое открытие расширяет ресурсы языка, добавляя к его запасам новые метафоры, так что язык по преимуществу развивается более экономичным и плодотворным способом - путем метафоризации. Следует, также, отметить, что благодаря метафоре существенно расширяются возможности информативной функции языка, создаются структуры, обладающие возможностью более точного отражения явлений действительности [3].

Мы полагаем, что изучение процессов метафоризации и метафоричности технических текстов является наиболее репрезентативной сферой, это связано с развитием научно-технического прогресса и научнотехнических знаний. Кроме того, необходимо отметить, что весь научный потенциал, в целом, на этапе реализации научного знания предполагает выход в систему обучения, культуры и прагматической деятельности, поэтому проблемы понимания при изложении сложнейших технических процессов имеют огромное значение, именно здесь решающим является умение использовать определенные средства языка, его универсальность и емкость.

Местом, позволяющим перейти с научного языка с его сложнейшими абстракциями на естественный язык и с естественного языка на научный, служит метафора, которая, как известно, основана на аналогии. Ассоциативные связи, возникающие при метафорическом переносе, имеют место благодаря фундаментальным человеческим концептам, которые являются врожденными, но их реализация зависит от языка как орудия культуры. Врожденность фундаментальных человеческих концептов можно объяснить тем, что наши категории и формы восприятия зафиксированы до нашего индивидуального опыта и адаптированы к внешнему миру [7].

В процессе метафорического творчества происходит концептуализация внеязыковой действительности в направлении от познания конкретного к познанию абстрактному. Известный советский психолог А.А. Леонтьев считает, что возникновение базовых концептуальных структур исходит из структурной природы опыта и врожденных способностей, благодаря которым происходит преломление конкретики на уровне абстракции [6].

Следует отметить, что человек, его тело, его организм, его физические, социальные и психические свойства и качества стали источником антропоморфных метафор в технических текстах по вычислительной технике.

Определяющая роль человеческого фактора в языке особенно широко проявляется в семантике метафоры. Антропоморфные метафоры широко представлены в научной картине мира, и, в частности, в технике. Антропоморфность и антропоцентризм, появляющиеся в метафоре, свидетельствуют о том, что человек осознал себя центром Вселенной, выделил себя из окружающего мира.

Антропоморфные метафоры, используемые в текстах по вычислительной технике, необходимы для передачи некоторого объема содержательной информации с минимальными языковыми затратами, коммуникативным и прагматическим эффектом. 